\title{
A praxis approach to financial literacy education
}

Financial literacy education (FLE) typically focuses on teaching skills and capabilities that promote individual wealth accumulation - for example, the importance of working, budgeting and saving. In this article, we argue the need to move from an individual wealth accumulation focus in FLE, to a praxis approach to FLE. We outline the shortcomings of the conventional approach to FLE and develop a conceptual framework for a praxis approach to FLE. We view praxis as the moral, ethical and caring aspect of teaching. Using the conceptual framework, we argue that a praxis approach to FLE includes full attention to: how financial decision-making affects others and self; acknowledging that some life decisions are not financially rewarding; understanding that improving financial mathematics skills and capabilities may not equate to an increase in income; considering how SES affects an individual's ability to save and maintain long-term saving; and the ways in which gender, culture, values, socioeconomic class and ethics shape identity and their impact on financial decision-making.

Keywords: financial literacy education, social justice, mathematics, praxis.

\section{Introduction}

Conventional approaches to financial literacy education (FLE) in its one-size-fits-all model focuses on individuals' deficits and ignores important factors that also affect individuals' financial decision-making. This approach fails to develop critical understandings needed for societal level change and may leave individuals who fail to develop wealth blaming themselves for a fate they had little control over. We argue that having financial knowledge and being able to apply financial knowledge are not the same for each individual. Influences such as 'behavioural/cognitive biases, selfcontrol problems, family, peer, economic, community and institutional' problems (Huston, 2010, p. 308), gender (Pinto \& Coulson, 2011) and culture (Author; Lahn, 2008; Pinto \& Chan, 2010) also affect financial decision-making. 
In this article, we argue the importance of moving from an individual wealth accumulation focus for teaching financial literacy to a praxis approach. The shortcomings of conventional FLE are outlined as we build a case for a new approach to FLE. A conceptual framework for a praxis (e.g. the moral, ethical and caring aspects of teaching (see Author, 2013) approach to FLE is developed.

The following research question guides this article: What might a praxis approach to FLE look like? A praxis approach to FLE includes acknowledgement that some life decisions are not financially rewarding but are still valuable; that improving financial mathematics skills and capabilities may not equate to increasing income; that full attention to how financial decisions affect self and others is required; that SES affects an individual's ability to save and maintain long-term savings; and that gender, culture, values, socioeconomic class and ethics shape identity and these will have an impact on individuals when they are faced with a financial decision. Without educators enacting FLE as a form of praxis, instruction will focus on the individual and their financial circumstances without due attention to the social structures that perpetuate wealth inequality. A praxis approach to FLE has the potential to reveal the shortcomings of the current financial landscape (Australian Securities and Investment Commission [ASIC], 2015) which has enabled predatory financial practices that are unlikely to be overcome by financial literacy (Author, 2018). Without attention to the social political arrangements that enable and constrain financial practices consumers may be overly trusting and vulnerable to exploitation.

\section{The push for financial literacy in schools}

Educating school students about personal finance has been acknowledged as essential by governments around the world (OECD, 2013). Lusardi (2015) argues that financial literacy is a 21 st century skill for students and that schools are best placed to develop 
the required skills and capabilities. Since the global financial crisis (GFC) of 2008, there has been increased interest in the financial literacy levels of citizens (OECD, 2012). Australia provides an interesting case study. Over the past decade, the federal government has invested millions of dollars and entrusted the ASIC to lead initiatives intended to help children understand finance. Australia has a "National Consumer and Financial Literacy Framework' (Ministerial Council for Education, Early Childhood Development and Youth Affairs [MCEECDYA], 2011) a document developed to ensure the economic and financial participation are fulfilled in the 'National Goals of Schooling 1999' (MCEECDYA, 2011). Soon after, the National Consumer and Financial Literacy Framework was developed by ASIC. Both policy documents guided and informed the framing of consumer and financial literacy within the Australian Curriculum (Australian Curriculum, Assessment and Reporting Authority [ACARA], 2017). The country also has 'National Financial Literacy Strategies' (ASIC, 2011, 2014), with the 2018 strategy open to public consultation at the time of writing this article.

In Australia financial literacy is positioned within the mathematics curriculum for the compulsory school years. In 2011, financial literacy's connection to mathematics was made explicit in numeracy with the sub-strand-money and financial mathematics - appearing under the broader strand of number and algebra. To support the teaching of financial literacy, ASIC funded the development of FLE resources for teachers to use based on the Australian Curriculum which are mapped to the Financial Literacy Framework (see MoneySmart Teaching ASIC, 2012). Although ASIC collects information about who downloads their resources it is difficult to ascertain whether downloading resources results in the resources being used in classrooms. Interestingly, Sawatzki and Sullivan (2017) report that despite more than $75 \%$ of teachers surveyed 
identifying as financially literate, only approximately half state they would be confident teaching financial literacy.

\section{Financial literacy defined}

The National Financial Literacy Strategies are described as a 'framework to guide policies and activities that aim to strengthen Australians' financial literacy and capability' (ASIC, 2018, para 1). Financial literacy is defined in this national strategy as 'a combination of financial knowledge, skills, attitudes and behaviours necessary to make sound financial decisions, based on personal circumstances, to improve financial wellbeing' (ASIC, 2014, p.6). As noted above, this definition focuses on the individual choosing to make effective financial decisions and implies that such choice will improve financial well-being.

In 2012, the Organisation for Economic Cooperation and Development (OECD) Programme for International Student Assessment (PISA) included a 'Financial Literacy Assessment' for 15-year-old students. When the results were released, media reports were congratulatory (Nancarrow, 2014), emphasising that Australia ranked in the top five of 18 participating countries and economies (Thomson, 2014). For that assessment, the OECD (2012) defined financial literacy as the:

knowledge and understanding of financial concepts, and the skills, motivation and confidence to apply such knowledge and understanding in order to make effective decisions across a range of financial contexts, to improve the financial well-being of individuals and society, and to enable participation in economic life. (pp.12-13)

We have included both definitions of financial literacy to demonstrate the similarities in the Australian and the globally used (OECD) definitions. We note that the OECD's definition acknowledges the importance of understanding financial concepts, being 
motivated to attend to money matters, having confidence and improving financial wellbeing not only for yourself, but for society as well, whereas the Australian definition focuses more on self, choice and attitudes. Both of these definitions represent conventional approaches to FLE that focus on working on one self (Arthur, 2014).

Davies (2015) argues that '[p]resent definitions of financial literacy are universally too limited and the responsibility for financial probity is placed on the individual, and responsibilities of the banks and government are ignored' (p. 312). The concept of financial literacy must include the behaviour of banks and governments, not just individuals to ensure that economic and FLE does not become a 'smokescreen, intended to divert attention from the behaviour of banks and governments' (Davies, 2015, p. 312). When financial probity is viewed as residing solely with the individual, there is the potential for those who experience financial hardship to be construed in ways that amount to victim blaming (Arthur, 2012; Pinto, 2013). Such constructions further distract from the need for government, financial regulators and the finance industry to assume shared responsibility for financial probity.

\section{Conventional approaches to FLE}

Like Australia, across the world most financial literacy programs and curricula follow what Lucey, Agnello and Laney (2015) describe as the conventional approach to FLE. The conventional approach is individually focused and considers how the financial decisions made by an individual affect the individual. There is an underpinning and misguided assumption in many conventional financial literacy initiatives that implies that acquiring financial skills and capabilities will contribute to individuals achieving financial well-being (Author, 2016a; Author \&, 2014). However, FLE is unlikely to 
reduce poverty, as individuals will still be constrained by more significant societal factors that result from the capitalist economic system. Societal factors that individuals have no control over include: the family one is born and/or adopted into; one's race, socio-economic status (SES), and one's parents and/or carer's educational background.

Haiven (2017) describes the individualistic or conventional approaches to FLE as being about 'where one is tasked with managing one's life as a savvy risk taker and empowered, individualistic economic agent' (p. 355). Positioning the individual's behaviour as effective or not means that individuals 'only have only themselves to blame for their successes or failures...[ignoring] the structural, systemic, and historical dimensions of exploitation, oppression, inequality, and discrimination' (p. $353)$.

\section{Criticality required in FLE}

FLE is now widely available to all citizens through compulsory schooling and/or other educational opportunities. Educational scholars (see Arthur, 2012; Author 2016; Lucey et al. 2015; Pinto, 2013 Sawatzki \& Sullivan, 2017) have advocated for critical approaches to FLE. These authors argue that changing one's financial circumstances is not as easy as it is often suggested in conventional approaches to FLE. Thus, there is an urgent need for critically informed approaches to FLE, that foster critical reflection and awareness of the structural conditions (Arthur, 2012). Attention is required to bring awareness to the possibilities for altering the structural conditions that may enable and constrain an individual's ability to have choice (Arthur, 2012).

\section{Conventional FLE missing the mark}

It is not clear if conventional approaches to FLE are effective even for accomplishing the identified goals. What is evident is that conventional approaches to FLE are not concerned with creating new conditions for living and working that are more equitable 
and socially just because conventional approaches focus on the role an individual instead of the government and financial services industry. Arthur (2012) posits that a financially literate individual is much more then someone who can decide between products and/or services, and understands the risks. As Pinto (2013) argued politics trumps evidence when it comes to FLE meaning that despite the importance of FLE, political interest in Canada was so strong that any evidence of FLE being ineffective was ignored in favour of teaching financial literacy to the masses. Indeed, Mandell and Klein's (2009) study with 79 high school students revealed that students who completed the personal financial management course were 'no more financially literate than those who had not' (p. 15).

\section{Moving towards transformative FLE}

Lucey et al. (2015) advocated for a critically compassionate approach to financial literacy and argued that individuals are not responsible for how they entered this world. The authors highlight that SES class is the result of institutions and structures that continue to reinforce how wealth is distributed, and that individual accomplishments are a result of personal choice and the environment. In the conventional approach to FLE, an individual's environmental circumstances, such as their family's SES, is often overlooked, with attention focused on individual financial responsibility through wealth accumulation practices. The critically compassionate approach to FLE is instead premised on social notions of care and compassion for all involved in the financial decision-making process unlike the conventional approaches to FLE that are premised on who controls resources.

In 2013 to 2015 the first author conducted research with a Canadian Aboriginal community to understand how FLE took shape in the community. She sought to identify the financial literacy needs with the community (instead of assuming a deficit) and 
worked with the community on sustainable FLE practices. The abovementioned research highlighted the inappropriateness of targeting individual on low incomes with a one-size-fits-all approach to FLE, with the aim of increasing financial well-being. Irrelevant content, examples that did not apply to the context and activities that were not tied to learning outcomes are some examples of how one-size-fits-all approaches were, on many accounts, useless (Author, 201_).

\section{An overview of the shortcoming of the conventional approach to FLE}

What seems to be lacking in the conventional approach to FLE is the need for criticality when navigating the financial landscape. Specifically, what is required is a FLE approach that moves beyond the 'budget and save' mantra. An approach to FLE that authentically engages teachers and students in considering the types of financial problems life holds in store, the multitude of choices associated with these problems, and the social and mathematical considerations that influence critically informed financial decision-making.

We are cautious about the motivations of financial institutions' involvement in FLE initiatives in schools. Therefore, there is a need for educators to be critically informed, even when financial institutions are explicit about their corporate social responsibility to help schools and teachers instil financial knowledge, skills and capabilities. Financial institutions have a vested interest in the outcomes of financial decisions about products they are promoting, whether these decisions emanate from critical information or not. At present financial institutions have full access using their 'category entitlement' expertise to attract a vulnerable group of primary students to open a savings account. These youth saving accounts often result in a lifelong relationship with the financial institution (Chalmers, 2017) that results in additional financial services and products such as credit cards, mortgages, and/or financial advice 
services and investment products. Such affiliates with one financial institution may create an environment of trust were caution and criticality are really required. Attention is now turned to outlining the shortcomings of the conventional approach to FLE, and in the process build a case for a new approach to FLE.

\section{Shortcoming A: The individualistic focus of FLE practices misidentifying the} root causes of financial fragility and resulting in victim blaming

The Australia and New Zealand (ANZ) bank's surveys (2015) have repeatedly found the lowest levels of financial literacy to be among those with less formal education; those with low household income or whose main source of income is a government benefit or allowance; those who speak a language other than English at home; and, those of Aboriginal or Torres Strait Islander descent. These findings perhaps reveal why adults with lower education levels living on low incomes are the targets of FLE offered by community organisations. In an international context, the 2012 and 2015 OECD PISA financial literacy assessment results revealed a strong relationship between student socioeconomic background and performance (Thomson, 2014; Thomson \& De Bortoli, 2017). Put simply, students from families with money typically perform better on test items about money. If FLE is focused on individual control over their own destiny and an individual performs poor on an assessment, then they may begin to blame themselves for their own lack of financial literacy and potential future success with finance. Knowing that assessment scores are correlated with family income means that results are mostly out of the control of individuals from low-income households. Furthermore, structural issues such as SES are more of a contributing factor for an individual's ability to experience financial wellbeing.

Taft, Hosein, Mehrizi and Roshan (2013) report a positive relationship between the variables of financial literacy, education and financial wellbeing. The 
authors found 'a higher level of financial wellbeing is followed by financial literacy' (p. 70) and that individuals with higher financial well-being also have reduced financial concerns. In their study, the demographic variables included age, sex, marital status and education levels, but SES was not included. However, Pinquart and Sörensen (2000) found that income (SES) is more strongly correlated with well-being than education, thus highlighting the role income plays in achieving financial wellbeing rather than an individual's level of financial literacy and/or education. However, Ritchie and Bates (2013) found that early success in mathematics and reading at age 7 resulted in a higher SES attainment at age 42, meaning that when education levels have a positive impact on income levels, then income levels may have an effect on well-being, as Pinquart and Sörensen (2000) reveal. Thus, the students who are not performing well on PISA financial literacy assessments (i.e. individuals from low SES backgrounds) and who have low educational achievement outcomes also find themselves living on low incomes and coping with financial stress. We are concerned about how 'blame' may be assigned to the individual for not acquiring financial literacy and achieving financial well-being when the role income plays in influencing financial well-being is not comprehended by those designing conventional FLE resources. Thus, conventional FLE ignores the root causes of SES and focuses individuals' attention on acquiring financial knowledge and skills instead of the important role developing a reliable source of income has on financial wellbeing.

Pinto (2013) argued that the GFC was the catalyst for victim blaming that moved the focus away from the financial institutions and onto individuals. The solution was simply that individuals lacked financial savvy to navigate their own finances and needed financial skills, knowledge and improved behaviour to correct 
these self-caused financial ills and consequences. Clarke (2015) refers to the idea that FLE will improve an individual's financial issues as the 'empty promise' of FLE; the empty promise being the gap between the complexities between understanding finance to make simple decisions and having 'advanced technical and specialist skills...required to successfully and autonomously negotiate contemporary financial market transactions, products, and innovations, on the other' (p. 2).

Victim blaming continued to gain momentum and was supported by a push for individual responsibility as the answer to a stronger economy. FLE was positioned as the answer to poverty, and became the focus and the solution to address financial fragility and was championed over improved financial regulation (Clarke, 2015; Willis, 2008).

Conventional approach to FLE's focus on individuals becoming financially resilient is problematic because acquiring financial skills and capabilities may have little impact on escaping a life in poverty. Clarke (2015) states that 'the incorporation of the resilience doctrine into FLE means that in "teaching finance" it also teaches failure' (p. 272). Under the resilience doctrine, it is assumed that FLE is always required, as the teachings never fail; only the individuals do when they 'fail to learn' (Clarke, 2015, p. 271). Thus, when a financial crisis occurs, more FLE is required, demonstrating a lack of resilience in the individual. Aligning teaching finance to teaching failure can be seen as being related to the misguided assumption that acquiring financial knowledge and skills will improve an individual's financial wellbeing whereas a good education and good income is more likely for what is required.

Van Treeck (2014) argued that personal debt was a temporary solution to combat rising inequality in the United States but that rising debt 'also contribut[ed] to the build-up of financial fragility' (p. 441). Leiser, Bourgeois-Gironde and Benita 
(2010) found that educated individuals with more social capital offered 'more impersonal and systemic, if not analytical, reading of the causes of the financial crisis' (p. 139) compared with individuals with less social capital who were less optimistic about the future of the economy. Therefore, economic leaders must demonstrate trust, integrity and decency to mend any financial turmoil (Pinto,2013). Without a more critical approach to FLE, individuals in lower positions on these scales will tend to blame individuals and be reticent to join essential movements aimed at reforming the more systemic causes.

\section{Shortcoming B: Category entitlement expertise leading FLE initiatives}

In Australia, financial regulation has served to limit the impact and fallout from the GFC. However, the push for improved financial education in schools was viewed as an opportunity that was embraced by the financial regulator (see ASIC, 2012) and financial institutions (Chalmers, 2017). By offering FLE in schools, representatives from financial institutions can offer 'category entitlement' (a term coined by Potter, 1996, p. 132) expertise under the guise of corporate social responsibility. 'Category entitlement' positions the financial services industry as experts in financial literacy and FLE, while undermining the valuable contribution of curriculum and pedagogical expertise by qualified educators in the classroom. Potter (1996) defines category entitlement as how individuals, through their association with their vocation and/or membership have unquestioned authority to speak on a particular topic. Stooke (2005) argued that this form of category entitlement dismisses the efforts, the need, and the role, of others involved in the process of educating. In this context, it is the teachers who are undermined as the financial industry/institutions are viewed as the authority and knowledge holders of quality financial education — although they may have little or no educational expertise and may be prone to one-size-fits-all approaches to 
teaching. The main concern about category entitlement is that the practitioner from the financial industry or institution is able to promote financial products and services that their association will ultimately benefit from and thus they position their needs ahead of the consumers' needs.

Taking a critical view of the field of FLE brings to the forefront the role financial institutions have in creating and controlling financial literacy narratives. This is evident in programs from all four of the major banks in Australia. The Commonwealth Bank prides itself on 'teaching generations of young Australians the importance of saving and lifelong money skills since 1931' through promoting its Dollarmite and Youthsaver bank accounts in schools. The Commonwealth Bank has re-launched Start Smart, which is a bank-branded FLE program for primary and secondary school students. The Australia and New Zealand Banking Group Survey of Adult Financial Literacy (2015), conducted every three years since 2003, is considered the leading measure of adult financial literacy, with the findings espoused to have broad implications for both the finance industry and financial literacy educators. The ANZ also has its MoneyMinded program, designed to build skills, knowledge and confidence in personal finance. The National Australia Bank (NAB) recently provided a new twist to financial literacy discourses, releasing research claiming to measure financial resilience. The concept of financial resilience is defined as 'the ability to access and draw on internal capabilities and appropriate, acceptable and accessible external resources and supports in times of financial adversity' (Centre for Social Impact \& NAB, 2015, p. 5). The Westpac bank has devised Financial First Steps, which are tailored workshops for schools, community or employer groups run by bank employees (Westpac, 2007). More recently, Westpac has partnered with Mathspace, a digital educational resource provider, and this partnership includes a 
Solve to Save program, where with an eligible Westpac bank account, children can earn $\$ 10$ per week for completing their maths homework.

In Australia, these are the four major banks, and in each case, their FLE initiatives are branded and encourage customers to bank with them through savings incentives. However, of concern is the ethics and financial practices promoted by financial institutions, particularly as recently a number of banking scandals have resulted in multiple government-led inquiries pertaining to their questionable financial practices (see Author, 2016b). This means that Australians are presently facing a range of concerning issues in their everyday interactions with the financial services industry, including examples of illegal practices and questionable ethics. Dodgy practices and a lack of ethics guiding financial decision-making was highlighted through a three-day parliamentary inquiry in October 2016 that delved into the troubling practices of the big four banks. These included

... tens of millions of dollars in 'errors', unscrupulous financial advice, forged documents and a number of examples of 'rockets and feathers' (interest rates shooting up like rockets when the RBA [Reserve Bank of Australia] raises the official rate and falling slowly, like feathers, when the cash rate falls (Lipson, 2016, para 3).

Thus, it would seem appropriate for financial institutions prioritize reforming their own practices over influencing the practices of individuals, in order to ethically maximize returns for shareholders.

Shortcoming C: Deficit perspectives driving conventional FLE

Being financial resilient may also mean that the conventional model of financial literacy teaches that a life of hardship is a life of failing to navigate finances effectively. Such an approach to FLE follows what Arthur (2014) refers to as FLE 
campaigns to improve oneself that removes the focus from the social structures that continue to perpetuate inequities. Therefore, being financial resilient is perhaps another attribute for individuals living on low incomes and/or facing financial hardship to acquire under conventional FLE practices. Such an approach lends itself to a deficit perspective to FLE since it is assumed the individual is lacking the skills, capabilities and attributes required to achieve financial well-being.

Clarke (2015) points out that under the logic of financial resilience, 'failures in FLE require more FLE' (p. 270). However, at present in Australia FLE resources are developed, funded and/or influenced by the very financial institutions and financial regulator that are 'failing' many. The implication is that financial literacy is certainly seen as important, but without a critical orientation to the field, it is in danger of being detrimental to many. Indeed vulnerable consumers being taken advantage of by financial agents working at financial institutions continues to be revealed in the Royal Commission into Misconduct in the Banking, Superannuation and Financial Services Industry in Australia. Evidence revealed by this Royal Commission highlights that banks do not have the consumers' best interests as their main priority. Nor does the financial regulator, which has ignored their own findings about the predatory financial practices in the funeral insurance industry that has deliberately targeted Aboriginal people with expensive and unsuitable products (see ASIC, 2015; Bainbridge \& Selvaratnam, 2018). There is also the emergence of financial schemes that enable individuals, including vulnerable consumers, to buy now and pay later and accumulate debt that currently escapes financial regulation by charging late fees instead of interest fees. It is, after all, not more financial literacy that is required to prevent predatory practices, but rather increased financial regulation and increased policing by the financial regulator. However, until increased financial regulation is in place and interim 
measure could be to educate individuals about how to identify and avoid predatory practices and the importance of regulation. What is needed is a shift in focus from what individuals may be lacking (deficit perspective) to the structural requirements that are needed to be put in place to protect vulnerable consumers from predatory practices.

\section{Shortcoming D: One-size-fits-all approach to FLE practices}

One-size-fits-all approaches to education do not consider the specific circumstances and conditions of each site (Kemmis et al. 2014). In the FLE context, one-size-fits-all approaches only consider the individual and how they can improve their circumstances, regardless of their specific circumstances and conditions. The relevance of the one-sizefits-all approach may only be suitable for a narrow, privileged sector of society (e.g., middle-class White males), as gender, culture and SES are not considered under this approach to FLE.

There is also a widespread belief that the sooner individuals are exposed to financial learning experiences, the better equipped they will be to make effective financial decisions in the future (Lusardi \& Mitchell, 2013; Author, 2013). Research by Mandell $(2004,2008)$ has revealed that, in general, financial education does not significantly lead to changed behaviour, albeit that the impact of education on behaviour change is difficult to measure. Moreover, Mandell (2008) found that teaching personal finance in high school has been shown to have little impact on increasing the low financial literacy levels of the students. It was found that when students participated in certain activities such as the stock market challenge, they were more likely to be financially literate (Mandell, 2008), suggesting that this activity could be an effective form of FLE.

Fernandes, Lynch and Netemeyer (2014) found that individuals seek FLE in a 'just-in-time' approach. A just-in-time approach is in tension with the one-size-fits-all 
approach to FLE practices that are not context specific or needs based. Moving towards a just-in-time approach would be strengthened by linking life stages and the identified needs of the participants. Furthermore, the impacts of other influences that may affect how an individual will make a financial decision are ignored under the conventional approach to FLE (Lucey et al., 2015). These influences include factors such as cultural beliefs about sharing resources and looking after one another (Author, 2016a), personal values about paid and unpaid work and child raising (Pinto \& Coulson, 2012), and other

gender biases that may challenge financial decision-making approaches. Indeed, navigating through the financial services product landscape is both complex and challenging, even for an individual with substantial and/or specialised financial education (Taylor \& Wagland, 2013). It is also the case that acquiring financial skills and capabilities does not mean that all individuals will be able to apply their newly acquired skills and capabilities —especially individuals on restricted incomes.

\section{Two alternative conceptions to financial literacy that challenge the conventional approaches to FLE}

Davies (2015) proposes a framework for financial literacy that is an alternative to conventional approach to financial literacy. His framework was developed to shift conventional conceptions of financial literacy that place all responsibilities on the individual to a framework that also includes the financial industry and government. The importance of understanding how the financial sector, regulation and government finances have an impact an individual's financial literacy is strongly argued. Davies (2015) posits that complex financial products and the narrative spun by the financial sector, which produces many financial literacy resources make it problematic for individuals to navigate their own financial literacy. In the framework, Davies (2015) outlines the role of individuals, financial services and government/country, and argues 
the importance of including financial behaviours of all three actors in definitions of financial literacy. In particular, he argues that '[f]inancial literacy may be judged according to understanding of short-term problems, understanding of longer term problems or understanding of relationships between short and longer term problems' (p. 311).

Lucey at al.'s (2015) alternative approach to conventional financial literacy is a 'critically compassionate approach to financial literacy' (p. $\mathrm{x})$. This approach is underpinned by care for self and others, trust, honesty and integrity. The authors delineate two views of financial literacy termed 'thin' and 'thick'; with the 'thin view' of financial literacy concerned with transactions and measured financial outcomes whereas the 'thick view of financial literacy recognizes that one's financial choices and decisions occur within a social system and affect the lives of other participants in that system' (p. 1). Lucey et al. argue that providing equitable FLE acknowledges the role the family you are born into, that both personal choice and environment have a role to play in accomplishments achieved, and that socioeconomic status exists because of 'institutional structures and procedures that maintain a concentration of wealth' (p. x).

Davies' (2015) and Lucey et al.’s (2015) alternative conceptions of financial literacy offer new approaches to FLE that move financial literacy from an individual responsibility to incorporate how other actors and social structures affect an individual's ability to be financial literate. These alternative conceptions of financial literacy are further discussed in the next section where we share some practical teaching examples using a praxis lens to unpack the practice of FLE. 


\section{Exploring FLE with a praxis lens - some practical examples}

Praxis is a particular kind of action. It is action that is morally-committed, and oriented and informed by traditions in a field. It is the kind of action people are engaged in when they think about what their action will mean in the world. Praxis is what people do when they take into account all the circumstances and exigencies that confront them at a particular moment and then, taking the broadest view they can of what it is best to do, they act. (Kemmis \& Smith, 2008,

p. 4)

Teaching financial literacy from a praxis perspective starts with acknowledging 'the connections among mathematics, financial literacy, and social justice' (Lucey \& Tanase, 2012, p. 9). In classrooms this might involve students exploring complex social problems, with the time to prepare and defend critical solutions. Such an approach may enable educators to 'infuse elements of social agency as well as financial literacy' (Lucey \& Tanase, 2012, p. 9), and compassion for one self and others (Lucey et al., 2015), and highlight the role the financial sector and government/country plays in financial literacy (Davies, 2015).

An alternative way to conceptualise financial literacy teaching and learning would be to critically explore the personal, social and ethical considerations to financial problem solving and decision-making as shown by both Davies (2015) and Lucey et al. (2015). An illustrative policy (not formal curriculum) example helps to show how this might be done. The National Consumer and Financial Literacy Framework specifies that at Year 6, students should be able to 'describe how an individual can influence their income' and 'explore the value of unpaid work to the community' (MCEECDYA, 2011, p.14). Presented as a provocation, this task is immediately relevant to primary school children and implies a desire to explore the various considerations families' balance in allocating human capital to paid and unpaid work opportunities. Financial 
literacy discourses found in conventional training documents (see Author \& 2017) imply a need to emphasize the importance of work — be it paid or unpaid. In Australia, questions of workforce participation are often values-laden, with reference being made to 'lifters and leaners'. The inference is that those who do not work place a strain on the economy. However, the reality is that the labour market is complex and workrelated decisions are influenced by a range of factors, often beyond an individual's immediate control, that might be productively explored through inquiry, even in early adolescence. Whereas an alternative approach to this task would be to describe what societal factors can influence an individual's income.

Exploring how an individual can influence their income provides an example of the inappropriateness of the conventional approach to financial literacy. If this question was discussed in a mixed SES classroom of students, where some students have not experienced financial hardship, this lesson has the potential to reaffirm a system of injustice, if time is not spent unpacking who owns, and does not own, property. A critical stance may be developed by both sets of students (eg. students from families with high and low SES backgrounds) by thoroughly unpacking who owns and does not own property.

Moreton-Robinson (2015) argues that ' the majority of Indigenous people in Australia do not have land rights, nor do they have legal ownership of their sacred sites' (p. 10). Intergenerational wealth transfers of property may be a long way off for many individuals living in poverty. The other discourse being perpetuated by the policy document example is the focus on how individuals can increase their income without factoring the aspect of social capital and what influence social capital may have on influencing one's income up or down. Social capital has been previously defined as 'the goodwill available to individuals or groups. Its source lies in the structure and content 
of the actor's social relations. Its effects flow from the information, influence, and solidarity it makes available to the actor' (Adler \& Kwon, 2002, p. 23).

Thus, the concern with the above-mentioned example is the positive spin put on an ideology of neutrality and blame. An alternative task to address the MCEECDYA recommendation is for primary-aged students to record the names and addresses of the banks (including whether they offer a full service or limited services), credit unions, pawn shops and pay-day lenders in the community (see Lucey et al., 2015). Such a task enables students to observe what income characteristics are associated with neighbourhoods that attract businesses and to consider why individuals might want to live in these neighbourhoods (Lucey et al., 2015). This task has the potential to orient students towards a perspective that is more socially just.

Teaching FLE calls for skilful and sensitive pedagogical approaches that help students to see that different individuals and families experience different financial realities often for reasons not of their choosing, but also contemplate the potential for social change. It is important to consider how the two approaches might resonate with, or marginalize, children in families affected by circumstances such as unemployment. Enabling praxis in the classroom provides opportunities for the educators to pause, reflect and enact the necessary modifications to the task. In the next section the praxis approach to FLE is articulated.

\section{The praxis approach: A conceptual framework}

A praxis approach to FLE is concerned with teaching financial decision-making that considers what influences an individual's decision and it affects others. We are building on Davies (2015) and Lucey et al.'s (2015) alternative conceptions of financial literacy in a new context by arguing the role of praxis by the FLE practitioner. We argue that a praxis approach includes full attention to: 
- comprehending how financial decision-making impacts others and self;

- acknowledging that some life decisions are not financially rewarding but often valuable and necessary;

- understanding that improving financial mathematics skills and capabilities may not equate to an increase in income;

- considering how SES impacts an individual's ability to save and maintain longterm savings; and,

- recognising the ways in which gender, culture, values, socioeconomic class and ethics shapes identity and what impact these factors have on an individual when faced with a financial decision (Author \& Author 2017; Author, 2016) (see Table 1).

<insert Table 1 about here>

The need for a praxis approach to FLE was unmasked by the first author during research in a Canadian Aboriginal community of which she is a member (see Author 2016). Considering that praxis is fundamentally about reflecting/thinking, acting and doing, we now turn our attention to education as praxis for financial literacy and how practitioners may be able to enact praxis in FLE (see Table 1). To this end, we provide recommendations for a praxis approach to FLE by unpacking each aspect of the approach.

\section{The impact of financial decision-making on others and self}

Davies (2015) proposed a framework for financial literacy that considers the short- and long-term interactions and outcomes of individuals, financial services and governments/countries. We build on Davies' (2015) framework to consider how financial decisions also move beyond the individual and affect other individuals by connecting Lucey et al.’s (2015) critically compassionate approach to financial literacy that consider how financial decisions require care for others.

To illustrate, in a 'Money and financial mathematics' (part of the number and algebra strand) lesson, Year 4 students (from a low SES school) are charged with the task of determining the best fundraising option for the school (an abbreviated version 
of the 'sausage sizzle' lesson in the Australian Curriculum for Year 4s). The lesson was taught with an inquiry-based mathematics approach (see Author et al. 2018), and the students were observed working in small groups of three to four. This inquiry approach to learning meant that students were scaffolded through the lesson, but the pedagogy was not particularly prescriptive and often students arrived at different solutions. Without prompting, some of the students adopted a compassionate approach to financial decision-making when solving this problem. This approach was demonstrated when they considered what was best for the consumers (they spoke about their own interests, their family, and school staff). What emerged during this collaborative group experience was that the students realised that their financial decision (i.e. the price they determined for their item(s) for sale) would have an impact on others. This care and concern for others was not part of the lesson as the focus on was on finding the 'best' fundraising option for the school. One group also expressed concern about borrowing money from the school to purchase the supplies required. This resulted in this group declaring that they would only borrow half of the amount to minimize the risk of not being able to repay the loan.

It is important to provide the opportunity for learners to comprehend, on a deeper level, how influences affect financial practice. This can be done by with students by discussing the possible influences of financial decision-making (i.e. SES, education level, personal and/or cultural values, life stage, environment, media and marketing, and social standing/profession). Examples from Author (2016) research also include how discomfort may be experienced when saving money when others are in need and how difficult it may be to increase an income without leaving the Community (a First Nation reservation). Discomfort may also be experienced when cultural beliefs collide with individual wealth accumulating practices, including a cultural belief about taking 
only what is needed and leaving the rest. Beliefs about money have been shown to affect financial behaviour (Klontz, Britt, Mentzer \& Klontz, 2011). Discussing and identifying different types of money beliefs and how the students feel their own beliefs influence their own behaviour with pocket money (received from allowance and/or cash gifts) could be a reflection exercise for students to work on in the classroom.

To foster engagement in financial decision-making in a classroom setting, students can be invited to consider the life stage they are at and to identify the financial decisions they are facing. The comments students share about the real financial dilemmas they are facing may also foster authentic discussions and opportunities to bring guest speakers into the classroom. By way of example, mobile phone options and cost-effective solutions for this age group may be relevant for their personal financial decision-making. A consumer researcher knowledgeable about mobile phones could be invited to discuss the students' concerns. Such an activity may also provide students with the agency required to have critical conversations with employees in mobile phone shops instead of being passive in the purchasing process. The ability to engage in critical conversations with this consumer researcher may also change the power relationship when students enter the mobile phone stores as consumers. Students as consumers can be equipped with the ability to critically thinking about the options and offers being presented to them instead of falling prey to sales tactics. Such critical thinking skills may lend themselves to other areas in life where these skills are required.

\section{Some life decisions are not financially rewarding but they are still valuable}

Roles such as a stay-at-home parent, a university student and/or a volunteer are all examples of valuable, important and often essential roles in society. Basing life decisions on what is deemed 'financially rewarding' or where the benefits outweigh the costs would omit the abovementioned roles and diminish their value. Indeed, 
individuals who are financially literate also make decisions that are important to their values and/or family needs over financially rewarding pathways (i.e. a stay-at-home parent and PhD student; see Author 2016). Fostering discussions and common understanding with students about their self-worth and how this is not necessarily tied to their families' financial wealth may also be valuable.

Another example for the classroom could involve exploring the value of volunteering experiences students may have participated in and/or would see value in participating in, as well as exploring the volunteer opportunities at their school to consider what might occur if volunteers did not occupy these positions.

\section{Improving financial skills and capabilities does not equate to an increase in income}

Being financially literate does not necessarily equate with financial well-being; that is, simply acquiring financial skills and capabilities such as learning what compound interest is and/or how to set financial goals does not necessarily mean you will experience an increase in financial well-being. Author (2016) refers to equating financial literacy with financial well-being as the false promise of conventional forms of FLE.

$\ldots$ the false promise of FLE... is much like understanding that just because a person cannot afford healthy diet choices does not mean they do not understand how to make those healthy choices. Both individuals who are financially literate and financially illiterate achieve financial well-being. It is often the wealthy financially illiterate individuals who are able to hide their ineffective financial decision-making by accessing adequate funds to enable their ways of being without financial stress. (Author, 2016, p. 236) 
The above quote illustrates the lived experiences of many; we have received anecdotal evidence over a number of years when individuals tell us after academic conference presentations that they are not financially literate but that they have the means (i.e. high income) to sustain their financial well-being. If acquiring financial skills and capabilities does not equate with financial well-being then the impact of other influences enabling and/or constraining financial practice needs to be understood by FLE educators.

To understand how acquiring financial skills and capabilities does not equate with an increase in income, students could self-reflect on the newly acquired financial skills and capabilities to consider how, when, and whether, such skills and capabilities have had a positive impact on their own income. Improving financial knowledge and skills is not necessarily helpful for improving the odds of financial well-being because income is a more important factor. Therefore, providing opportunities for students to explore how they might be able to increase their income (by reducing expenses and/or increasing their income through another job) could also be discussed and/or selfreflected upon.

\section{The impact of SES on individuals' ability to save and maintain long-term savings}

Lea et al. (1993) argue that individuals living on low incomes are unable to save and maintain long-term savings. Yet, often it is the individuals living on low incomes who are targeted by the generic one-size-fits-all FLE workshops. Thus, engaging students in collaborative discussions with their peers provides opportunities for students to develop their ability to think critically about social inequities that matter to them and others and how social inequities affect financial practice. Moreover, Moreton-Robinson (2015) argues that assuming that " "we" all have the same chances' and that '[a]ny 
failure to achieve is the fault of the individual...denies the existence of the privileges' (p. 96). Providing students with opportunities to unpack the social structures that continue to perpetuate inequalities in society may foster a more critically informed reading of society. Moreover, the conversations that students have in the classroom may enable thoughtful consideration about how financial practices are experienced by others and affect others. Through critical conversations about social class and privilege, critically informed learners may be developed. Critical pedagogical practices may also lead to more respectful relationships in the classroom (Lucey \& Tanase, 2012) and students may step into certain practices (that promote collective well-being) and out of other practices (that are self-serving and at the expense of others).

Through collaborative learning opportunities in the classroom students may also understand why certain relationships are formed and the practice architectures that may enable and constrain financial practice. For example, students from low SES backgrounds may be able to identify what constrains their financial practices and also identify what may enable others' (from higher SES brackets) financial practices.

\section{Gender, culture, values, socioeconomic class and ethics shape identity and}

\section{financial decision-making}

FLE should recognise that gender, culture, values, socioeconomic class and ethics influence financial decision-making and choice. It is recommended that FLE is tailored to suit the needs of the participants. Without such recognition FLE will continue to be what it ought not to be -- gender and SES blind, culturally void, value neutral, and ethically misguided.

Gustein (2003) argues that through mathematics, power and inequities between different social groups can be taught to students so that they 'understand explicit discrimination based on race, class, gender, language, and other differences' (p. 45). 
FLE is well placed for discussions about colonisation and how loss of property has affected individuals' SES. This type of understanding of the social world permits students to 'identify relationships and make connections between them' (Gustein, 2003, p. 45). Lucey and Tanese (2012) describe culturally responsive mathematics as engaging students in critical thinking through the students' own lens of understanding based on their environment and the relationships they hold.

The pedagogical implication of gender, culture, values, SES and ethics and how they shape identity and financial decision-making can be linked to Lucey et al.'s (2015) statement about how we do not choose the family we are born into and that an individual's self-worth is not based on their SES. When students understand that selfworth is not equated with SES, they are then able to critically unpack assumptions about social class. The way students think about their own self-worth and the self-worth of others may permit further unpacking of how certain activities and relationships occur between various SES groups. Furthermore, self-reflection and/or classroom dialogue about self-worth not being based on SES may help students gain agency by dismissing the idea that self-worth is dependent on the financial resources of parents or families.

With regard to financial decision-making, students may also have the opportunity to unpack how certain financial decisions may be made based on personal and/or cultural beliefs. Thus, critical conversations could occur about what may enable or constrain financial decision-making based on personal and/or cultural beliefs. Such conversations will permit students to realise the complexities around financial decisionmaking when thinking about how financial decision-making affects self and others. Last, how the personal ethics of individuals affects their financial decision-making is another area to unpack, and this could be done by looking at unethical financial decisions that have received media attention. An example from Australia that received 
media attention is the role of banks in schools teaching financial literacy. Exposed by the media is the financial incentives Bankers receive and how brand loyalty is what is gained not financial skills and knowledge.

\section{Concluding comments}

This article contributes to the growing body of critical financial literacy research and how a praxis approach to FLE can be applied to transform teachers' practices in school classrooms. We advocate for a praxis approach to FLE that challenges the conventional approach for the sake of humanity and promotes a world worth living in (Kemmis et al., 2014). In this article, a praxis approach for FLE has been articulated and exemplified that moves beyond individual wealth-accumulating approaches to FLE approaches that consider the impact of financial decisions on others and what influences financial decision-making. If education is for the betterment of the individual and society, the focus on the individual may need to include a focus on care, compassion and concern for self and others and building collaborations with others. Identifying, exposing and challenging the inequalities in society may provide students with more awareness to critically examine the injustices in their communities and social worlds.

We concur with Sawatzki's (2014) argument that FLE practices that focus on exploring socially and critically age-appropriate 'financial dilemmas' (p. 3) and how they affect self and others are required. By shifting the focus of FLE from individual wealth-accumulating practices to the impact of financial decisions on others may assist with critical scholarship around FLE practices. Thinking about the need for criticality with regard to conventional FLE practices may require unpacking the FLE discourses such as financial resilience. Moreover, challenging the dominant FLE discourses may lead to enacting changes in FLE approaches that move from an individualistic approach towards a praxis approach. 
FLE from a praxis approach involves moving towards a more socially just approach to teaching and learning financial literacy. A praxis approach to FLE involves placing the role of financial education back in the educators and parents hands instead of '[r]elying on financial institutions' to determine the nature of financial education' (Davies, 2015, p. 312), as financial institutions FLE practices seem to create a brand affinity and preference towards a particular financial institution. Having financial institutions in classrooms appears to be narrow and self-serving and is potentially contributing to social reproduction of existing injustice.

The praxis approach targets a broader conception of what it means to be critically financially literate, with greater potential for positively influencing systems and social change. A praxis approach is about transformation. Through teaching financial literacy with an emphasis on students developing with their peers a 'sociopolitical consciousness, a sense of agency, and positive social and cultural identities' (Gustein, 2003, p. 40), the interrelationships between financial decision-making, social justice and mathematics are exposed and may be transformed.

Acknowledgements, have been removed in this version of the manuscript.

\section{References}

Adler P., \& Kwon, S. W. (2002). Social capital: Prospects for a new concept. The Academy of Management Review, 27(1), 17-40. doi:10.2307/4134367

Arthur, C. (2012). Financial literacy education for citizens: What kind of responsibility, equality and engagement? Citizenship, Social and Economics Education, 11(3), $163-176$. 
Arthur, C. (2014). Financial literacy education as a public pedagogy: Consumerizing economic insecurity, ethics and democracy. In Aprea, C., Wuttke, E., Breuer, K., Koh, N.K., Davies, P., Greimel-Fuhrmann, B., Lopus, J.S. (Eds.), International handbook of financial literacy (pp. 113-125). Singapore: Springer.

Australian Curriculum, Assessment and Reporting Authority (ACARA). (2017). Australian Curriculum. Retrieved from https://australiancurriculum.edu.au Australia and New Zealand Banking Group Limited (ANZ). (2015). Survey of adult financial literacy in Australia. Melbourne, Australia: The Social Research Centre.

Australian Securities and Investments Commission (ASIC). (2011). Financial literacy and behaviour changes. Sydney, Australia: Australian Securities and Investments Commission.

Australian Securities and Investment Commission (ASIC). (2012). MoneySmart teaching links to Australian curriculum. Retrieved from http://teaching.moneysmart.gov.au/professional-learning/teaching-consumerand-financial-literacy/section-3/links-to-australian-curriculum

Australian Securities \& Investments Commission (ASIC). (2014). National Financial Literacy Strategy 2014-2017. Retrieved from http://www.financialliteracy.gov.au/media/546585/report-403 nationalfinancial-literacy-strategy-2014-17.pdf

Australian Securities \& Investments Commission (ASIC). (2015). Funeral insurance: A snapshot. Retrieved from https://download.asic.gov.au/media/3393361/rep454-published-29-october2015.pdf 
Australian Securities \& Investments Commission (ASIC). (2018). Strategy 2018:

Shaping a national strategy for 2018. Retrieved from

http://www.financialliteracy.gov.au/strategy-and-action-plan/financialliteracy-strategy/strategy-2018

Bainbridge, A., \& Selvaratnam, N. (2018, July 1). Bankng royal commission to look at funeral insurance that 'targets vulnerable people'. Retrieved from http://www.abc.net.au/news/2018-07-01/banking-royal-commission-funeralinsurance-vulnerable-people/9910496

Centre for Social Impact and National Australia Bank (2016). Financial resilience in $\begin{array}{llll}\text { Australia } & 2015 . & \text { Retrieved }\end{array}$ http://www.csi.edu.au/media/uploads/Financial_Resilience_in_Australia_-

\section{Full Report.pdf}

Chalmers, S. (2017, October 13). CHOICE leads charge to keep banking giant CBA out of primary schools. Australian Broadcasting Corporation (ABC). Retrieved from http://www.abc.net.au/news/2017-10-13/choice-leads-charge-to-keepbank-cba-out-of-primary-schools/9047648

Clarke, C. (2015). Learning to fail: Resilience and the empty promise of financial literacy education. Consumption Markets \& Culture, 18(3), 257-276. doi:10.1080/10253866.2014.1000315

Davies, P. (2015). Towards a framework for financial literacy in the context of democracy. Journal of Curriculum Studies, 47(2), 300-316. doi:10.1080/00220272.2014.934717

Fernandes, D., Lynch, J. G., \& Netemeyer, R. G. (2014). Financial literacy, financial education, and financial behaviours. Management Science, 60(8), 1861-1883. 
Gutstein, E. (2003). Teaching and learning mathematics for social justice in an urban, Latino school. Journal of Research in Mathematics Education, 34, 37-73.

Haiven, M. (2017). The uses of financial literacy. Financialization, the racial imagination, and the unpayable debts of settler colonialism. Cultural Politics, 13(3), 348-369.

Huston, S. J. (2010). Measuring finacial literacy. The Journal of Consumer Affairs, 44(2), 296-316. doi: 10.1111/j.1745-6606.2010.01170.x

Kemmis, S., \& \& Grootenboer, P. (2008). Situating praxis in practice: Practice architectures and the cultural, social and material conditions for practice. Amsterdam, the Netherlands: Sense Publishers.

Kemmis, S., Wilkinson, J., Edwards-Groves, C., Hardy, I., Grootenboer, P., \& Bristol, L. (2014). Changing practices, changing education. Singapore: Springer Science \& Business Media.

Klontz, B., Britt, S., Mentzer, J., \& Klontz, T. (2011). Money beliefs and financial behaviors: Development of the Klontz money script inventory. The Journal of Financial Therapy, 2(1), 1-22. doi:10.4148/jft.v2il.451.

Lahn, J. (2008). Aboriginal people, money and financial literacy: Shepparton in a national context. My Moola Opening Financial Pathways Program Evaluation Report 2007-2009. Canberra, Australia: Centre for Aboriginal Economic Policy Research, The Australian National University.

Lea, S.E.G., Webley, P., \& Levine, R.M. (1993). The economic psychology of consumer debt. Journal of Economic Psychology 14, 85-119.

Leiser, D., Bourgeois-Gironde, S., \& Benita, R. (2010). Human foibles or systemic failure-Lay perceptions of the 2008-2009 financial crisis. The Journal of Socio-Economics, 39, 132-141. 
Lipson, D. (2016, October 7). Banking inquiry: What have we learnt and where to from here? Australian Broadcasting Corporation. Retrieved from http://www.abc.net.au/news/2016-10-06/banking-inquiry-what-have-welearnt/7910414

Lucey, T. A., Agnello, M. F., \& Laney, J. D. (2015). A critically compassionate approach to financial literacy. Rotterdam, the Netherlands: Sense Publishing.

Lucey, T. A., \& Tanase, M. (2012). Making learning to problem-solve count: Critical use of mathematics to bring about social justice. Multicultural Education, 19(4), 8-13.

Lusardi, A. (2015). Financial literacy skills for the 21st century: Evidence from PISA. Journal of Consumer Affairs, 49, 639-659. doi:10-1111/joca.12099

Lusardi, A., \& Mitchell, O. S. (2013). The economic importance of financial literacy: theory and evidence. Cambridge, MA: National bureau of economic research.

Mandell, L. (2008). Financial education in high school. In A. Lusardi (Ed.), Overcoming the saving slump: How to Increase the effectiveness of financial education and saving programs (pp. 257-279). Chicago, IL: University of Chicago Press.

Mandell, L. (2004). Financial literacy: Are we improving? Washington, DC: Jump\$tart Coalition for Personal Financial Literacy.

Mandell, L., \& Klein, L. (2009). The impact of financial literacy education on subsequent financial behavior. Journal of Financial Counselling and Planning, 20(1), 1-10.

Ministerial Council for Education, Early Childhood Development and Youth Affairs (MCEECDYA). (2011). National Consumer and Financial Literacy Framework (Revised 2009). Retrieved from 
http://www.curriculum.edu.au/verve/_resources/National_Consumer_Financial_L iteracy_Framework_FINAL.pdf

Moreton-Robinson, A. (2015). The White possessive. Property, power and Indigenous sovereignty. Minneapolis, MN: University of Minnesota Press.

Nancarrow, K. (2014, November 14). How to turn a teenager into a financially savvy $\begin{array}{llll}\text { adult. } & \text { The } & \text { Age. } & \text { Retrieved }\end{array}$ http://www.theage.com.au/national/education/how-to-turn-a-teenager-into-afinancially-savvy-adult-20141110-11jp29.html

Organisation for Economic and Cooperative Development (OECD). (2013). Assessment and analytical framework: Mathematics, reading, science, problem solving and financial literacy. Paris: OECD Publishing. doi:http://dx.doi.org/10.1787/9789264190511-7-en

Organisation for Economic and Cooperative Development (OECD). (2012). PISA 2012 financial literacy assessment framework. PISA: OECD Publishing.

Pinquart, M., \& Sörensen, S. (2000). Influences of socioeconomic status, social network, an competence on subjective well-being in later life: A meta-analysis. Psychology and Aging, 15(2), 187-224.

Pinto, L. E. (2013). When politics trump evidence: Financial literacy education narratives following the global financial crisis. Journal of Education Policy, 28(1), 95-120.

Pinto, L. E., \& Chan, H. (2010). Social justice and financial literacy. Are gender and socio-cultural equity missing from the discussion? Our Schools, Our Selves, 19(2), 61-77. 
Pinto, L. E., \& Coulson, E. (2011). Social justice and the gender politics of financial literacy education. Journal of the Canadian Association for Curriculum Studies, $9(2), 54-85$.

Potter, J. (1996). Representing reality: Discourse, rhetoric and social construction.

Thousand Oaks, CA: Sage.

Ritchie, S. J., \& Bates, T. C. (2013). Enduring links from childhood mathematics and reading achievement to adult socioeconomic status. Psychological Science, 24(7), 1301-1308.

Sawatzki, C. M. (2014). Connecting social and mathematical thinking: Using financial dilemmas to explore children's financial problem-solving and decision-making. Unpublished doctoral dissertation, Monash University, Melbourne, Australia.

Sawatzki, C. M.,\& Sullivan, P. A. (2017). Teachers' Perceptions of Financial Literacy and the Implications for Professional Learning. Australian Journal of Teacher Education, 42(5). http://dx.doi.org/10.14221/ajte.2017v42n5.4

Stooke, R. (2005). OP-ED 'Many hands make light work' but 'too many cooks spoil the broth': Representing literacy teaching as a 'job for experts' undermines efforts to involve parents. The Journal of Curriculum Studies, 37 (1), 3-10. doi:10.1080/0022027042000236154.

Taft, M. K., Hosein, Z. Z., Mehrizi, S. M. T., \& Roshan, A. (2013). The relation between financial literacy, financial wellbeing and financial concerns. International Journal of Business and Management, 8(11), 63-75.

Taylor, S., \& Wagland, S. (2013). The solution to the financial literacy problem: What is the answer? Australasian Accounting Business \& Finance Journal, 7(3), 69-90. 
Thomson, S. (2014). Financing the future: Australian students' results in the PISA 2012 financial literacy assessment. Melbourne, Australia: Australian Council for Educational Research.

Thomson, S., \& De Bortoli, L. (2017). PISA 2015: Financial literacy in Australia. Melbourne, Australia: Australian Council of Educational Research.

Van Treeck, T. (2014). Did inequality cause the U.S. financial crisis? Journal of Economic Surveys, 28(3), 421-448. doi:10.1111/joes.12028

Westpac. (2007). Westpac community involvement 2007. Retrieved from https://www.westpac.com.au/docs/pdf/aw/sustainability/2007_Community_In volvement_Report.pdf

Willis, L. E. (2008). Against financial-literacy education. Iowa Law Review, 94, $197-$ 285. 